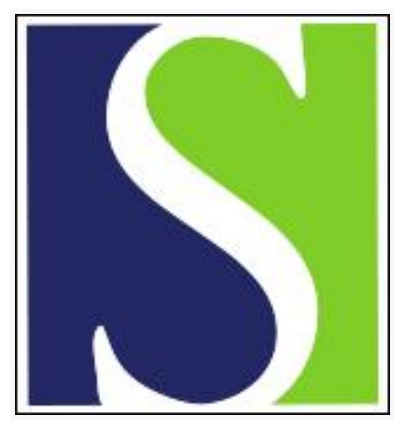

Scand J Work Environ Health 2019;45(1):90-97

https://doi.org/10.5271/sjweh.3754

Published online: 18 Jul 2018, Issue date: 01 Jan 2019

Promoting health and physical capacity during productive work: the Goldilocks Principle

by Holtermann A, Mathiassen SE, Straker L

A large potential for improving occupational health remains unexploited by a limited focus on preventing health impairments by reducing physical activity at work. The Goldilocks Principle aims to promote health and physical capacity by designing physical activity during productive work to be "just right". If effective, the Goldilocks Principle has a great potential to contribute in solving major work-related challenges of our time.

Affiliation: Andreas Holtermann, Professor, PhD, National Research Centre for the Working Environment, Copenhagen, Denmark. aho@nrcwe.dk

Refers to the following texts of the Journal: 2017;43(6):526-539 2017;43(1):24-33 2015;41(2):140-152 2010;36(5):357-365 1984;10(6):403-408

Key terms: ergonomics; Goldilocks Principle; health capacity; health promotion; occupational health; physical activity; physical capacity; physical work demand; productive work; sedentary behavior; workplace health promotion

This article in PubMed: www.ncbi.nlm.nih.gov/pubmed/30021029 


\title{
Promoting health and physical capacity during productive work: the Goldilocks Principle
}

\author{
by Andreas Holtermann, PhD, ${ }^{1,2}$ Svend Erik Mathiassen, PhD, ${ }^{3}$ Leon Straker, PhD ${ }^{4}$
}

\begin{abstract}
Holtermann A, Mathiassen SE, Straker L. Promoting health and physical capacity during productive work: the Goldilocks Principle. Scand J Work Environ Health. 2019;45(1):90-97. doi:10.5271/sjweh.3754
\end{abstract}

\begin{abstract}
Objectives In spite of preventive efforts, organizations and employees face several challenges related to working life and occupational health, such as a substantial prevalence of musculoskeletal disorders, social inequality in health and physical capacity, multi-morbidity, an obesity epidemic and an aging workforce. We argue that a new approach to occupational ergonomics and health is required, going beyond prevention of harm caused by work. We propose the "Goldilocks Principle" for how productive work can be designed to promote health and physical capacity.

Methods Physical (in)activity profoundly influences health and physical capacity, with effects depending on the extent and temporal structure of the (in)activity. Like the porridge, chair and bed that needed to be "just right" for Goldilocks in the The Three Bears fairytale, physical activity during productive work needs to be "just right" for promoting rather than deteriorating health and capacity. In many jobs, physical activity is, however, either too much/high/frequent or too little/low/infrequent to give positive biomechanical and cardiometabolic stimuli.

Results This paper presents the rationale, concept, development, application and prospects of the Goldilocks Principle for how productive work can be designed to promote health and physical capacity.

Conclusions We envision a great potential to promote health and physical capacity by designing productive work according to the Goldilocks Principle, thus leading to benefits with respect to the current challenges related to working life and occupational health for society, organizations and employees.
\end{abstract}

Key terms ergonomics; health promotion; occupational health; physical activity; physical work demand; sedentary behavior; workplace health promotion.

In spite of extensive preventive efforts, employees, organizations and societies experience an increasing burden from several major challenges. Musculoskeletal pain is the leading cause of years lost to disability, with growing consequences for life quality, work participation and productivity all over the world (1). High occupational physical activity demands are generally considered to be among the main contributors to musculoskeletal pain (2). Further, the prevalence of multi-morbidity (several co-existing health impairments) is currently increasing (3). Similarly, the obesity epidemic is spreading across the world (4) causing an increased incidence of health impairments, healthcare costs and work ability loss (5), with the increasing prevalence of sedentary work seen as an important explanation (6). Thus, initiatives to ensure that workers can be kept healthy to maintain an active working life are urgently needed (7). These health impairment changes are occurring at a time when workplaces are increasingly complex and facing demographic and economic changes. The demographic shift to older populations in high-income societies is creating extensive age-related increases in health impairments, work ability loss and reductions in the proportion of inhabitants financially contributing to society and welfare systems (8). Furthermore, social inequality in health is increasing (9). Among people in the labor market, the challenges just mentioned are greater in low-status, low-income, blue-collar jobs. Blue-collar workers often have manual, strenuous work tasks (eg, heavy lifting and carrying, pushing and pulling, awkward postures

1 National Research Centre for the Working Environment, Copenhagen, Denmark.

2 Department of Sports Science and Clinical Biomechanics, University of Southern Denmark, Odense, Denmark.

3 Centre for Musculoskeletal Research, Department of Occupational and Public Health Sciences, University of Gävle, Gävle, Sweden.

4 School of Physiotherapy and Exercise Science, Curtin University, Perth, Western Australia, Australia.

Correspondence to: Andreas Holtermann, Professor, PhD, National Research Centre for the Working Environment, Copenhagen, Denmark. [E-mail: aho@nrcwe.dk] 
and repetitive tasks) (10), which evidence links to an increased risk for health impairments (eg, musculoskeletal pain), sickness absence and early retirement $(11,12)$.

These growing occupational health and working life challenges call for reconsideration of the current preventive occupational ergonomic paradigms and suggest the need for new actions. For this reason, we first present two major current ergonomic paradigms addressing occupational health, which we term the "occupational physical activity minimization paradigm" and the "workplace exercise paradigm", and we provide arguments for why these paradigms cannot solve the aforementioned main challenges for occupational health and working life. Then, we introduce the rationale and basic principles for a new approach for how productive work can be designed to promote health and physical capacity, termed "the Goldilocks Principle". We describe a procedure for how to address and change productive work according to this principle, and how a job constructed using this approach may look. Finally, we discuss implications for occupational health research and practice.

\section{The occupational physical activity minimization paradigm}

For decades, high strenuous physical activity at work has been considered the predominant cause for excessive fatigue and discomfort, musculoskeletal pain, health impairments and concurrent premature withdrawal from the workforce (13). The main preventive initiative has therefore been to reduce excessive physical activity at work, using the concept of "the less - the better" (14). Since the ultimate goal of this approach has been to prevent work-related harm by minimizing the physical activity at work to the extent possible, we term it the "occupational physical activity minimization paradigm". This approach has been the dominating preventive occupational ergonomic approach for decades, not only among blue-collar workers, but also among office workers.

Facilitated by legislation, mechanization, automatization and implementation of technical ergonomic aids, this preventive paradigm has led to a reduction of physical activity at work in many occupations across the whole spectrum of industries (e.g. forestry, mining, construction, manufacturing, elder care). Despite this, the mentioned main challenges of occupational health and working life have not been solved to any notable extent; if anything, they have escalated. For example, in Denmark the prevalence of workers reporting musculoskeletal pain, high physical exertion and fatigue after work has not reduced, but rather increased since 2010, despite extensive implementation of ergonomics aids and principles for proper working technique, increased automatization, and protective legislation.

The fact that physical activity at work has decreased in many occupations without a concomitant reduction in the prevalence of health impairments can be considered a paradox. However, over the last decade, an alternative explanation for these health impairments of the general working population has emerged. This explanation is based on the health risk of spending much time of the day sedentary, observed to be associated with metabolic and cardiovascular disorders, reduced physical capacity, and increased risk of musculoskeletal pain and mortality (15). Extensive time spent being sedentary is not only found among office workers, but also in many blue-collar occupations (16). Given the evidence showing ill-health to be associated with extensive sedentary time, the basic idea of the occupational physical activity minimization paradigm, ie, to reduce physical activity demands at work as much as possible, makes literally no sense. Instead, this paradigm may comprise a cause rather than a solution for the main challenges of occupational health and working life mentioned above. Accordingly, a new occupational prevention paradigm targeting the lack of fitness-improving physical activity of the working population has developed.

\section{The workplace physical exercise paradigm}

This prevention approach, termed "the workplace physical exercise paradigm" has emanated from two main concepts. The first concept is based on the general notion in occupational physiology that the physical activity performed during work does not have an intensity and temporal structure leading to improved physical fitness and health, but rather it may cause health impairments if the worker physical capacity is not sufficiently high to handle the workload (17) (18). Thus, there has been a rising concern that a large proportion of blue-collar workers do not have the required physical capacity for tolerating the physical activity demands encountered at work (19). The ultimate goal of this concept of the workplace physical exercise paradigm has been to facilitate a good balance between the physical activity demands at work and the physical capacity of the workers by enhancing worker physical capacity through performing workplace physical exercise (20). By increasing the physical capacity of the worker, the relative physiological workload on the worker when performing a given physical activity task will be reduced (21), and this improved work ability is assumed to prevent development of health impairments. An example from a blue collar job is a RCT among cleaners consisting of aerobic exercise for one hour per week during working hours to investigate the effects on cardiorespiratory fitness, relative physiological workload and health (22). The intervention was shown to be effective for improving cardiorespiratory fitness, reducing the relative cardiorespiratory load during work (heart rate) and improving a 
wide variety of health parameters (23) (24). Moreover, physical exercise during working hours has been shown to increase physical capacity (eg, muscle strength) and reduce musculoskeletal pain in many manual jobs, like slaughterhouse and healthcare $(25,26)$.

The second concept of this paradigm is based on the growing knowledge of the negative health effects of too much sitting (sedentariness), and that offering physical exercise during working hours may reduce health-impairments from excessive sedentary work. This paradigm is often implemented by organizing exercises during breaks from productive work or promoting active commuting to work. Examples of this paradigm are to provide a gym at the workplace and arrange walks and exercise in breaks from productive work. Physical exercise during breaks from productive work and active commuting to work has, indeed, been successful in improving health (eg, reducing musculoskeletal pain) among white-collar workers with primarily sedentary work (27).

Although the workplace physical exercise paradigm has been documented to promote health of both blueand white-collar workers, it has several limitations. These are that (i) physical exercise during working hours causes lost time from productive work, (ii) the physical exercise promotes worker physical capacity and health only, without modification of the physical activity demands at work, which in many cases can be the main cause of the health impairments, (iii) the workers with the highest need for exercise appear to have it offered less often and take it up even less often (28), (iv) the physical exercise at work is predominantly based on individual motivation and is thus vulnerable to barriers like time constraints making it difficult to make sustainable (29), and (v) offering exercise to all workers is not particularly cost-efficient compared to changing the work, since it requires training of each new employee to the point of being sufficiently fit to manage the work. Due to these limitations, we argue that the workplace physical exercise paradigm is not able to handle the current main challenges of occupational health and working life and a new paradigm that could better address these issues is needed.

\section{Rationale and fundamentals of the Goldilocks Principle}

The Goldilocks Principle is inspired by the Three Bears fairytale where Goldilocks tries the porridge, chairs and beds, finding some too hot/large/hard, some too cold/ small/soft, but some "just right" for her needs. Like the fairytale, the Goldilocks Principle aims to design productive work to be "just right" with respect to physical activity, with the ultimate aim of improving the health and physical capacity of the worker (30).

When physical activity during productive work is not "just right" it is well documented to result in health impairment, rather than promote health and physical capacity (31). Physical activity of too high mechanical strain (eg, lifting of very heavy objects) can cause musculoskeletal pain, too frequent physical activity can lead to excessive fatigue, and too much prolonged standing can lead to musculoskeletal symptoms and varicose veins (30). On the other hand, too little mechanical strain leads to bone and muscle loss, too infrequent moderate/vigorous physical activity leads to cardiorespiratory deconditioning, and too little standing or walking leads to cardiometabolic impairments (30).

Physical activity is considered to be "just right" when the timeline of exposure and recovery of different body systems and functions, eg, the cardiorespiratory, metabolic or musculoskeletal systems, offers sufficient stimulus to improve function (but not so much stimulus that functions deteriorate), while at the same time allowing sufficient recovery for the systems to build up and a "training effect" to develop (but not so much recovery that inactivity prevails) (17). The "just right" physical activity is therefore characterized by timelines of exposures (eg, postures, movements, forces) that combine exposure intensities, frequency and duration in patterns leading to improved health and capacity, as opposed to combinations causing disorders and deteriorated capacity. In a productive work setting, physical activity in accordance with the Goldilocks Principle should therefore consist of work stimulating a range of body systems while at the same time allowing adequate rest and recovery for the body to positively adapt to the physical activity. This may, for instance be achieved by redesigning jobs to consist of work tasks with ample diversity (32). An example is garbage workers, who often work in teams of two. One worker drives the vehicle while the other worker performs all manual handling (pushing and pulling garbage bins) while walking at a fast pace. In this work organization, the driver is sedentary for several hours per day not having the sufficient stimuli on the musculoskeletal and cardiovascular systems, while the other worker experiences a high mechanical load on his shoulders, back and knees at a high cardiorespiratory intensity without sufficient periods of rest (33). When designing work in accordance with the Goldilocks Principle, the two workers would take turns driving the truck and handling the bins, so both of them get a better balance between sufficient stimuli of the musculoskeletal and cardiovascular systems to get a "training effect" and sufficient seated rest for recovery.

The aim of the Goldilocks Principle is to improve health and physical capacity by designing productive work to be "just right" is in contrast with the "occupational physical activity minimization paradigm" which aims to prevent health impairment by reducing excessive physical activity at work. While both the "workplace exercise paradigm" and the Goldilocks Principle aim to 
promote health and physical capacity of the workers, the main difference between them is that while the workers take breaks from their productive work to perform the exercise in the workplace exercise paradigm, the Goldilocks Principle aims to offer a "just right" pattern of physical activity through productive work tasks. With this approach, positive effects on health and physical capacity have the potential to reach all workers (both blue- and white-collar workers) without being costly for the company. This offers a cost-effective solution which is sustainable as it is not dependent on the motivation of the individual worker and does not require every new employee to be trained to a high level sufficient to be productive.

The Goldilocks Principle builds upon the wellestablished concept in ergonomics of "fitting the task to the human" by adding that "the task should also make the human fit". Like "vision zero" for serious accidents at work, we see the Goldilocks Principle as a new ambitious strategy in occupational health and working life, striving for productive work to be just right for improving health and physical capacity. It might not be feasible to design productive work to optimize health and physical capacity in every job, but even in jobs where the Goldilocks principle cannot be realized with current technology, we argue that thinking and acting in accordance to this principle will lead to better jobs that are, at least, not harmful to health. However, possible negative effects on health of implementing the Goldilocks Principle should also be considered and evaluated. As an example, the risk of short-term injuries may be increased by introducing intense activities at work for the purpose of increasing physical capacity (14).

\section{Procedure for designing productive work to promote health and physical capacity}

When designing productive work in accordance with the Goldilocks Principle, we recommend the following 4-steps procedure: (i) assessing the current work situation and potential for change, (ii) assessing the current worker status and potential for change (iii) specifying the goal, and (iv) reorganizing or modifying current work tasks according to the Goldilocks Principle to meet goals.

Step 1: Assessing the current work situation and potential for change. The main characteristics of work (eg, specific work content and job tasks, availability of ergonomic aids, organization of work, job autonomy, social support, and collaboration between workers and management) differ extensively between sectors and jobs. These characteristics are well known to be important for developing, implementing and ensuring effectiveness of workplace interventions. As a first step, it is therefore important to develop an overview of these work characteristics by workplace observations, interviews with managers and employees, and examining available written information from the organization. As part of this overview, an analysis of the physical activity demands at work is needed. Thus, an assessment will address the current work tasks and their relative occurrence in the organization, the physical activity demands associated with those tasks, and the current distribution of tasks among workers.

Step 2: Assessing the current worker status and potential for change. Several characteristics of the workers need to be taken into account when designing work in accordance to the Goldilocks Principle. Characteristics of importance could be age, gender, musculoskeletal health and functional limitations, physical capacity, knowledge about physical activity and health, and motivation for behavioral change. For example, physical capacity determines the relative workload for performing a given physical work task. Thus, a work task of lifting $20 \mathrm{~kg}$ boxes with a given frequency will cause a larger physiological strain (relative workload on the body) on a worker with low capacity than for a worker with a highbox-lifting physical capacity. Moreover, a worker with high cardiorespiratory fitness has a higher capacity for recovery following physical activity tasks compared to a worker with low cardiorespiratory fitness (34). Thus, a given physical activity at work might improve health for one worker (eg, a worker with sufficiently high physical capacity for tolerating the physical activity task and achieving the needed recovery for performing the work the next day), but can impair the health of another worker (with low physical capacity who does not have adequate time for needed recovery before performing the work the next day) (21). Therefore, it is of importance to assess the characteristics of the worker which may be of importance for the physiological workload of performing a given productive work task (relative strain on the body). These characteristics may include: age (ie, generally higher physiological workload and poorer recovery capacity with higher age), gender (ie, generally higher physiological workload and poorer recovery capacity for females than males), BMI (ie, higher physiological workload and poorer recovery capacity with BMI $>25 \mathrm{~kg} / \mathrm{m}^{2}$ ), musculoskeletal symptoms and reduced physical function (ie, higher physiological workload and poorer recovery capacity with musculoskeletal symptoms and reduced physical function), and physical capacity (ie, higher physiological workload and poorer recovery capacity with lower cardiorespiratory fitness and muscle strength).

Moreover, designing work in accordance to the Goldilocks Principle needs to consider the context of the whole person, including both their work and non-work 
activities. For example, changes in physical activity at work may cause unintended compensation out of work (reduced sitting at work can increase sitting during leisure time) (35). For this reason, it is important that designing work in accordance to the Goldilocks Principle does not lead to unfavorable behaviors during non-work time, eg, due to excessive fatigue. Rather, work in accordance with the Goldilocks Principle ought to be balanced with non-work demands and opportunities for recuperation. For example, workers who train heavily for sports in leisure time may need to sit down at work to recuperate adequately, while other workers who are mainly sedentary during leisure time may need to be physical activity at work to maintain health and physical capacity. Thus, designing work according to the Goldilocks Principle needs to take account of the individual worker's entire 24/7/52 physical activity.

Step 3: Specifying the goal. Then, the goal needs to be specified based on the retrieved knowledge of the current work situation, potential for change and the worker status and potential for change. Even though work according to the Goldilocks Principle has the overarching aim of promoting health and physical capacity, the specific goal can vary depending on characteristics of the work tasks, worker and context, and thus be decisive for how the productive work needs to be redesigned. The specific health and capacity in need of improvement strongly depends on both the physical activity demands and characteristics of the work as well as on the characteristics of the worker. Moreover, the goal will determine how to design the physical activity at work in according to the Goldilocks Principle. For example, a goal of improving cardiorespiratory fitness will require design of work tasks involving large muscle groups of high intensity, a goal of increasing metabolic health will require work tasks involving large muscle groups over longer durations, and a goal of increasing muscle strength will require work tasks activating specific muscle groups at higher intensity for shorter durations.

\section{Step 4: Reorganizing or modifying current work tasks accord- ing to the Goldilocks Principle to meet goals. If the analysis} of current work indicates a potential for modifying and/ or re-organizing current tasks and jobs to better reflect the Goldilocks Principle, three major initiatives may be considered for redesigning current productive work in according with the principle. The three approaches may be combined to obtain an even better effectiveness.

(i) Changing how to perform the tasks. This initiative involves changes in how the worker performs the work tasks. An example can be implementation of a sit-stand workstation or another activity-permissive workstation for an office worker, where the worker is offered the possibility to vary body posture and to be physically active while performing the same work task.

(ii) Changing time-pattern of work tasks. The time pattern of current work tasks can be arranged according to the Goldilocks Principle. This may be possible even when the work tasks of a worker are difficult to modify. For example, the work tasks in hotel room cleaning can be difficult to modify, but redesign of the time-pattern of the work tasks may be performed, promoting a healthy physical activity and rest pattern over the day.

(iii) Introducing new tasks. An effective approach for changing productive work in accordance with the Goldilocks Principle can be to introduce new tasks into the jobs of workers that deviate from those already performed. An example of this is to change the jobs of individual workers by re-arranging available tasks in the organization so as to promote exposure variation within workers rather than having this variation between workers. This may be possible even when both the work tasks and the time pattern of how they are performed are hard to modify. For example, the work tasks of an individual worker in a manufacturing production line is often too constrained (both in work content and time-pattern) to be modified to become just right, but introducing new work tasks with markedly different physical activity characteristics has been proposed to be feasible for sustainable implementation, even though truly effective cases have not appeared in the scientific literature to any major extent (36).

Deciding which type(s) of modification or re-organization of job tasks to choose and how to implement it in the organization ought to be based on the information gathered in the previous steps and by active involvement of all levels of the organization (ie, management, supervisors and employees). Moreover, the implementation and effects of workplace Goldilocks interventions ought to be evaluated with respect to costs and effectiveness.

\section{How could work according to the Goldilocks Principle look like?}

To further clarify the Goldilocks Principle for work design we provide four examples.

Example 1-Office work. Excessive sitting is documented to increase the risk for impaired health. Office workers have been measured to sit about 5.5 hours during working hours and often in long continuous bouts (37). Thus, an example of design in accordance to the Goldilocks Principle for office workers would be to implement sit-stand stations to enable substitution of some sitting with some standing at suitable time periods, arrange structured walking meetings and promoting to use the stairs rather than the elevator. This has been shown to reduce sitting time at work and promote the health of office workers (37). This example shows how tasks can 
be redesigned to be performed in different ways and with a different time pattern.

Example 2 - Childcare work. Childcare workers have much static standing and sedentary work with a high prevalence of musculoskeletal symptoms and sickness absence. Thus, modification of childcare work in accordance with the Goldilocks Principle ought to replace some static standing and sitting with fast walking and/ or running to improve their health and physical capacity. For example, taking the children out for a run or walks on a regular basis several times a week would be beneficial for the health and physical capacity of the childcare workers, as well as for the children. This is an example of bringing in new work tasks improve health and physical capacity of the workers.

Example 3 - Suburban train drivers. Suburban train drivers have work characterized by prolonged sitting with occasional walking and rare high exertion to manually change linkages etc. Goldilocks Principles would encourage the enrichment of their jobs to create more scheduled brief walks (for example to do a perimeter check of the train every ten stations) and also more regularly (several times each week) perform high exertion tasks to maintain strength. More long-term solutions could include redesign of cabs to allow sitting and standing while driving. Changing the way tasks are performed and bringing in new tasks are approaches used in this example.

Example 4-Hospital staff. A large hospital houses a variety of supportive tasks and jobs, some of which entail mainly sedentary work (receptionists, secretaries) while others are characterized by substantial physical workloads (cleaners, porters). Cleaning requires much walking and standing with few possibilities for periods of recovery while sitting (23), and cleaners are well documented to have poor musculoskeletal and cardiovascular health and capacity. While supportive hospital jobs are normally performed by specialists employed for only that specific purpose, they may represent sufficient diversity to be combined in an effective job redesign according to Goldilocks principles. For instance, combining cleaning with tasks in the reception at a regular basis would lead to days with cleaning workloads that may be sufficient to improve physical capacity and days in the reception providing the recovery needed.

\section{Implication for research and practice}

Foremost, it is important to note that the effectiveness of the Goldilocks Principle is so far, hypothetical. Thus, following a recent research model (2), the Goldilocks Principle needs to be scientifically tested with respect to the extent to which the "just right" contents and structure of physical activity during productive work will (i) be effective in promoting health and capacity, (ii) not cause negative side-effects, (iii) be feasible in different occupations, given the existing prerequisites, (iv) be accepted, adapted and implemented in real organizations, (v) be possible to scale up to reach widely across organizations.

If the scientific evaluation of the mentioned aspects of the Goldilocks Principle shows positive results, we envision a large potential to promote health and physical capacity among the working population. Especially, we consider the potential for sustainable promotion of health and physical capacity if the design of work according to the Goldilocks Principle also imposes beneficial effects on work quality or productivity.

In the Norwegian Governmental Work Environment Act, it is stated that "the purpose of the Working Environment Act is to ensure safe working conditions and equal treatment among workers and to ensure that the working environment forms a basis for a health-promoting and meaningful work situation". Specifically, employers are required to consider initiatives for promoting physical activity among their employees. Thus, by stating that it is the responsibility of the employers to consider initiatives for promoting physical activity at the workplace, the Norwegians have already taken the step further than focusing on prevention of harm from work only.

Both for research and practice in ergonomics, occupational and public health, we see the Goldilocks Principle as a new and needed opportunity to meet the mentioned main challenges of occupational health and working life for organizations and employees. With respect to research, it might also provide more societal focus and significance. Moreover, introducing the Goldilocks Principle can also improve the balance in the fields of ergonomics occupational health between focusing on risk factors and focusing on promotion of health and physical capacity; which may create more engagement of labor market partners, insurance and pension funds, organizations and employees.

\section{Concluding remarks}

A large potential for promoting health and physical capacity is unexploited by the prevailing occupational physical activity minimization paradigm, which exclusively focus on preventing health impairments by reducing physical activity demands at work. While the workplace exercise paradigm aims to promote health and physical capacity, it has several limitations representing barriers for reach and sustainable implementation among the workers in greatest need for intervention. We envision a great potential in the Goldilocks Principle as an alternative to these two paradigms because it aims to 
promote health and physical capacity by designing physical activity during productive work to be "just right".

Designing work in accordance to the Goldilocks Principle has the potential to reach all workers, including lower socioeconomic groups. Thus, the Goldilocks Principle could contribute to reduce the increasing socioeconomic health gap in many societies. Further, because the principle is about making productive work "just right", both for those with too much and too little physical activity at work, we see a great potential for the Goldilocks Principle to improve health and capacity for both white- and blue-collar workers.

Due to its basis in productive work, we consider the Goldilocks Principle to have a good potential for behavior change, with improved health, physical capacity and work quality and productivity, which ought to have good chances for sustainability.

We emphasize that the Goldilocks Principle has not yet been scientifically evaluated, which is desirable before attempting to implement it widely at workplaces. Researchers are encouraged to evaluate the feasibility and effectiveness of the Goldilocks principle in a variety of occupational groups.

If shown to be effective, we consider the Goldilocks Principle to have a great potential in contributing to handle major societal challenges of our time, such as the substantial prevalence of musculoskeletal disorders, social inequalities in health and physical capacity, multi-morbidity, the obesity epidemic, and demographic challenges, including an aging workforce.

\section{References}

1. Buchbinder R, van Tulder M, Öberg B, Costa LM, Woolf A, Schoene M et al.; Lancet Low Back Pain Series Working Group. Low back pain: a call for action. Lancet 2018 Jun;391(10137):2384-8. http://dx.doi.org/10.1016/S01406736(18)30488-4.

2. van der Beek AJ, Dennerlein JT, Huysmans MA, Mathiassen SE, Burdorf A, van Mechelen W et al. A research framework for the development and implementation of interventions preventing work-related musculoskeletal disorders. Scand J Work Environ Health 2017 Nov;43(6):526-39. http://dx.doi. org/10.5271/sjweh.3671.

3. Barnett K, Mercer SW, Norbury M, Watt G, Wyke S, Guthrie B. Epidemiology of multimorbidity and implications for health care, research, and medical education: a crosssectional study. Lancet 2012 Jul;380(9836):37-43. http:// dx.doi.org/10.1016/S0140-6736(12)60240-2 .

4. Afshin A, Forouzanfar MH, Reitsma MB, Sur P, Estep K, Lee A et al.; GBD 2015 Obesity Collaborators. Health Effects of Overweight and Obesity in 195 Countries over 25 Years. N Engl J Med 2017 Jul;377(1):13-27. http://dx.doi. org/10.1056/NEJMoa1614362.
5. Gregg EW, Shaw JE. Global health effects of overweight and obesity. N Engl J Med 2017 Jul;377(1):80-1. http:// dx.doi.org/10.1056/NEJMe1706095.

6. Kohl HW 3rd, Craig CL, Lambert EV, Inoue S, Alkandari JR, Leetongin G et al.; Lancet Physical Activity Series Working Group. The pandemic of physical inactivity: global action for public health. Lancet 2012 Jul;380(9838):294 305. http://dx.doi.org/10.1016/S0140-6736(12)60898-8.

7. Wallace E, Salisbury C, Guthrie B, Lewis C, Fahey T, Smith SM. Managing patients with multimorbidity in primary care. BMJ 2015 Jan;350:h176. http://dx.doi.org/10.1136/bmj. h176.

8. Reeuwijk KG, van Klaveren D, van Rijn RM, Burdorf A, Robroek SJ. The influence of poor health on competing exit routes from paid employment among older workers in 11 European countries. Scand J Work Environ Health 2017 Jan;43(1):24-33. http://dx.doi.org/10.5271/sjweh.3601.

9. Donkin A, Goldblatt P, Allen J, Nathanson V, Marmot M. Global action on the social determinants of health. BMJ Glob Health 2018;3(Suppl 1). http://dx.doi.org/10.1136/ bmjgh-2017-000603

10. Andersen LL, Fallentin N, Thorsen SV, Holtermann A. Physical workload and risk of long-term sickness absence in the general working population and among blue-collar workers: prospective cohort study with register follow-up. Occup Environ Med 2016 Apr;73(4):246-53. http://dx.doi. org/10.1136/oemed-2015-103314.

11. van den Berg TI, Elders LA, Burdorf A. Influence of health and work on early retirement. J Occup Environ Med 2010 Jun;52(6):576-83. http://dx.doi.org/10.1097/ JOM.0b013e3181de8133.

12. Andersen LL, Mortensen OS, Hansen JV, Burr H. A prospective cohort study on severe pain as a risk factor for long-term sickness absence in blue- and white-collar workers. Occup Environ Med 2011 Aug;68(8):590-2. http:// dx.doi.org/10.1136/oem.2010.056259.

13. Roffey DM, Wai EK, Bishop P, Kwon BK, Dagenais S. Causal assessment of workplace manual handling or assisting patients and low back pain: results of a systematic review. Spine J 2010 Jul;10(7):639-51. http://dx.doi. org/10.1016/j.spinee.2010.04.028.

14. Straker L, Mathiassen SE. Increased physical work loads in modern work--a necessity for better health and performance? Ergonomics 2009 Oct;52(10):1215-25. http:// dx.doi.org/10.1080/00140130903039101.

15. Young DR, Hivert MF, Alhassan S, Camhi SM, Ferguson JF, Katzmarzyk PT et al.; Endorsed by The Obesity Society; Physical Activity Committee of the Council on Lifestyle and Cardiometabolic Health; Council on Clinical Cardiology; Council on Epidemiology and Prevention; Council on Functional Genomics and Translational Biology; and Stroke Council. Sedentary Behavior and Cardiovascular Morbidity and Mortality: A Science Advisory From the American Heart Association. Circulation 2016 Sep;134(13):e262-79. http://dx.doi.org/10.1161/CIR.0000000000000440.

16. Hallman DM, Sato T, Kristiansen J, Gupta N, Skotte 
J, Holtermann A. Prolonged Sitting is Associated with Attenuated Heart Rate Variability during Sleep in Blue-Collar Workers. Int J Environ Res Public Health 2015 Nov;12(11):14811-27. http://dx.doi.org/10.3390/ ijerph121114811.

17. Åstrand PO, Rodahl K. Textbook of work physiology. Physiological bases of exercise. New York: McGraw-Hill Book Company, 1986.

18. Holtermann A, Krause N, van der Beek AJ, Straker L. The physical activity paradox: six reasons why occupational physical activity (OPA) does not confer the cardiovascular health benefits that leisure time physical activity does. Br J Sports Med 2018 Feb;52(3):149-50. http://dx.doi. org/10.1136/bjsports-2017-097965.

19. Holtermann A, Mortensen OS, Burr H, Søgaard K, Gyntelberg F, Suadicani P. Physical demands at work, physical fitness, and 30-year ischaemic heart disease and all-cause mortality in the Copenhagen Male Study. Scand J Work Environ Health 2010 Sep;36(5):357-65. http://dx.doi. org/10.5271/sjweh.2913.

20. Holtermann A, Jørgensen MB, Gram B, Christensen JR, Faber A, Overgaard $\mathrm{K}$ et al. Worksite interventions for preventing physical deterioration among employees in job-groups with high physical work demands: background, design and conceptual model of FINALE. BMC Public Health 2010 Mar;10:120. http://dx.doi.org/10.1186/14712458-10-120.

21. Ilmarinen J, Louhevaara V, Korhonen O, Nygård CH, Hakola T, Suvanto S. Changes in maximal cardiorespiratory capacity among aging municipal employees. Scand J Work Environ Health 1991;17 Suppl 1:99-109.

22. Korshøj M, Krustrup P, Jørgensen MB, Prescott E, Hansen $\AA \mathrm{M}$, Kristiansen $\mathrm{J}$ et al. Cardiorespiratory fitness, cardiovascular workload and risk factors among cleaners; a cluster randomized worksite intervention. BMC Public Health 2012 Aug;12(12):645. http://dx.doi. org/10.1186/1471-2458-12-645.

23. Korshøj M, Lidegaard M, Skotte JH, Krustrup P, Krause N, Søgaard K et al. Does aerobic exercise improve or impair cardiorespiratory fitness and health among cleaners? A cluster randomized controlled trial. Scand J Work Environ Health 2015 Mar;41(2):140-52. http://dx.doi.org/10.5271/ sjweh.3475.

24. Korshøj M, Birk Jørgensen M, Lidegaard M, Mortensen OS, Krustrup P, Holtermann A et al. Decrease in musculoskeletal pain after 4 and 12 months of an aerobic exercise intervention: a worksite RCT among cleaners. Scand J Public Health 2017 Jul. [Epub ahead of print]. https://doi.org/10.1177/1403494817717833.

25. Rasmussen CD, Holtermann A, Bay H, Søgaard K, Birk Jørgensen M. A multifaceted workplace intervention for low back pain in nurses' aides: a pragmatic stepped wedge cluster randomised controlled trial. Pain 2015 Sep;156(9):1786-94. http://dx.doi.org/10.1097/j.pain.0000000000000234.

26. Sundstrup E, Jakobsen MD, Jay K, Brandt M, Andersen LL.
High Intensity Physical Exercise and Pain in the Neck and Upper Limb among Slaughterhouse Workers: Cross-Sectional Study. BioMed Research Internat 2014;2014:218546.

27. Chen X, Coombes BK, Sjøgaard G, Jun D, O'Leary S, Johnston V. Workplace-Based Interventions for Neck Pain in Office Workers: Systematic Review and Meta-Analysis. Phys Ther 2018 Jan;98(1):40-62. http://dx.doi.org/10.1093/ $\mathrm{ptj} / \mathrm{pzx} 101$.

28. Jørgensen MB, Villadsen E, Burr H, Mortensen OS, Holtermann A. Does workplace health promotion in Denmark reach relevant target groups? Health Promot Int 2015 Jun;30(2):318-27. http://dx.doi.org/10.1093/heapro/ dat041.

29. Malik SH, Blake H, Suggs LS. A systematic review of workplace health promotion interventions for increasing physical activity. Br J Health Psychol 2014 Feb;19(1):14980. http://dx.doi.org/10.1111/bjhp.12052.

30. Straker L, Mathiassen SE, Holtermann A. The 'Goldilocks Principle': designing physical activity at work to be 'just right' for promoting health. Br J Sports Med 2018 Jul;52(13):818-9.

31. Holtermann A, Hansen JV, Burr H, Søgaard K, Sjøgaard G. The health paradox of occupational and leisure-time physical activity. Br J Sports Med 2012 Mar;46(4):291-5. http://dx.doi.org/10.1136/bjsm.2010.079582.

32. Mathiassen SE. Diversity and variation in biomechanical exposure: what is it, and why would we like to know? Appl Ergon 2006 Jul;37(4):419-27. http://dx.doi.org/10.1016/j. apergo.2006.04.006.

33. Kuijer PP, van der Beek AJ, van Dieën JH, Visser B, Frings-Dresen MH. Effect of job rotation on need for recovery, musculoskeletal complaints, and sick leave due to musculoskeletal complaints: a prospective study among refuse collectors. Am J Ind Med 2005 May;47(5):394-402. http://dx.doi.org/10.1002/ajim.20159.

34. Ilmarinen J. Physical load on the cardiovascular system in different work tasks. Scand J Work Environ Health 1984 Dec;10(6 Spec No):403-8. http://dx.doi.org/10.5271/ sjweh.2303.

35. Alkhajah TA, Reeves MM, Eakin EG, Winkler EA, Owen N, Healy GN. Sit-stand workstations: a pilot intervention to reduce office sitting time. Am J Prev Med 2012 Sep;43(3):298-303. http://dx.doi.org/10.1016/j. amepre.2012.05.027.

36. Padula RS, Comper ML, Sparer EH, Dennerlein JT. Job rotation designed to prevent musculoskeletal disorders and control risk in manufacturing industries: A systematic review. Appl Ergon 2017 Jan;58:386-97. http://dx.doi. org/10.1016/j.apergo.2016.07.018.

37. Danquah IH, Kloster S, Holtermann A, Aadahl M, Bauman A, Ersbøll AK et al. Take a Stand!-a multi-component intervention aimed at reducing sitting time among office workers-a cluster randomized trial. Int J Epidemiol 2017 Feb;46(1):128-40.

Received for publication: 27 April 2018 